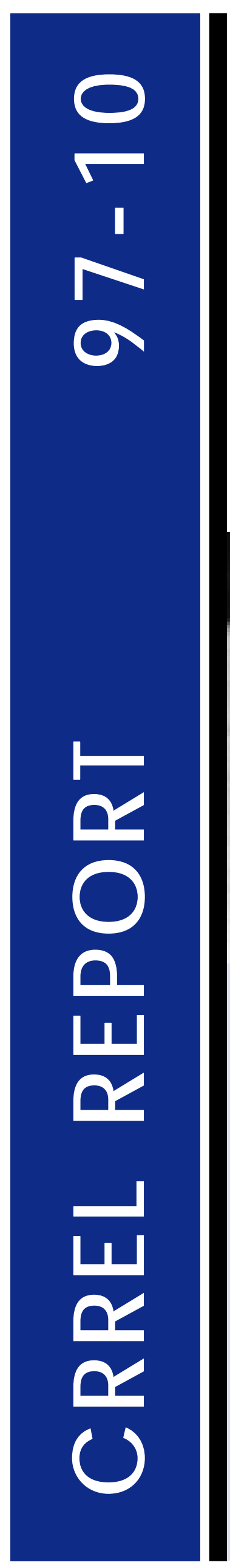

A Review of Sintering in Seasonal Snow

Samuel C. Colbeck

December 1997

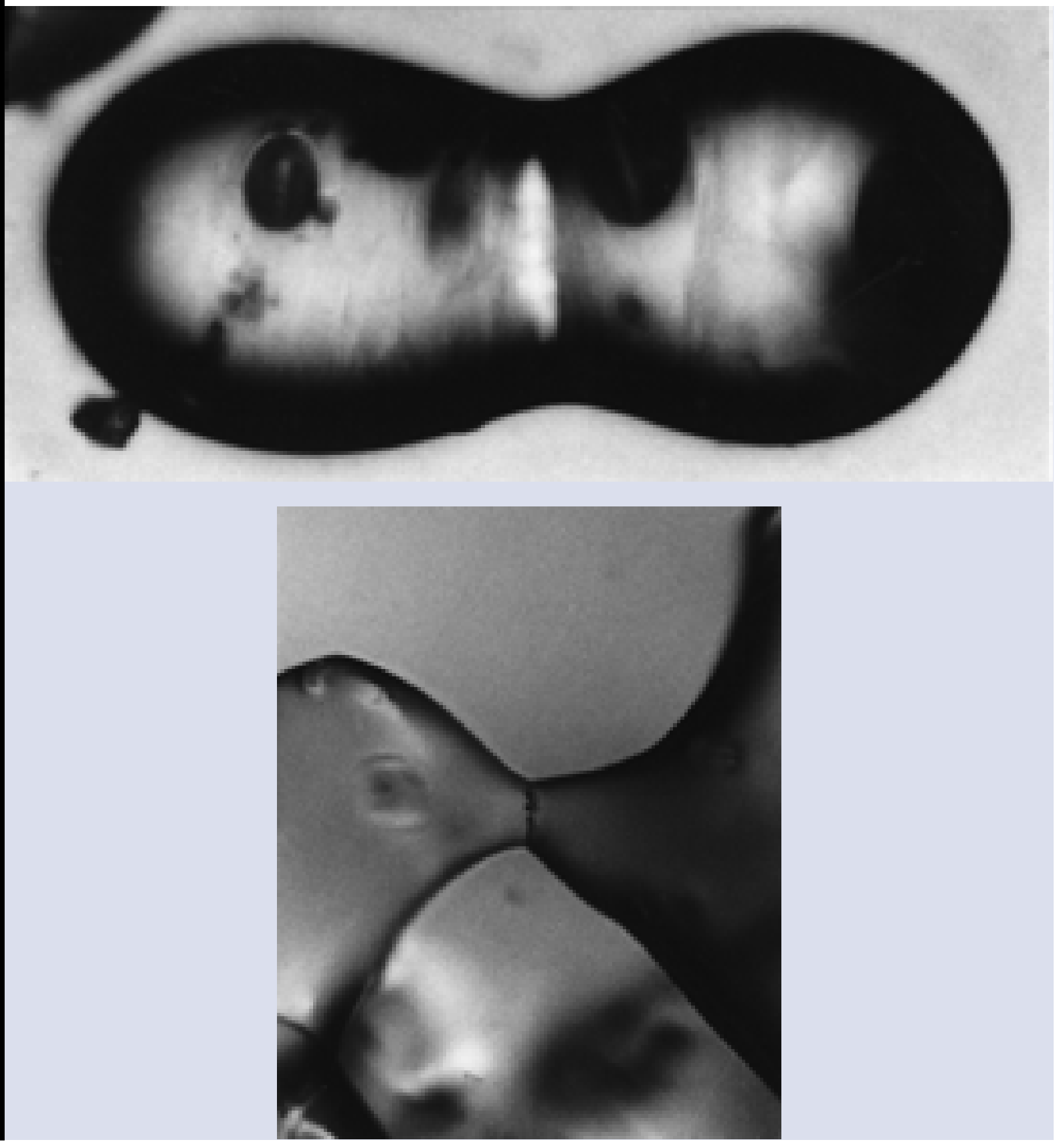


Abstract: Strength and electrical pathways develop in snow as bonds grow among grains. Strong ice-to-ice bonds form in wet snow at low liquid contents but not in highly saturated wet snow. In freely draining wet snow, grain clusters form, and these require a certain configuration among the three phases of water. This depends somewhat on the number of grains in the cluster, but always leads to bonding. In dry snow, bonds form more slowly, but considerable strength can develop as long as rounded grains develop. The rate of bond growth is probably controlled by the temperature gradient, because both grains and bonds are observed to grow very slowly in dry snow in the absence of a temperature gradient. The basic shape of the bonds is dictated by the geometrical requirements of grain-boundary grooves and is not a simple concave neck. In dry snow, this shape, and possibly the processes, have been misunderstood.

Cover: Two sets of sintered particles: the upper photo is of sintered glass beads, and the lower is of sintered snow grains, showing a grain boundary and grain boundary groove.

\section{How to get copies of CRREL technical publications:}

Department of Defense personnel and contractors may order reports through the Defense Technical Information Center:

DTIC-BR SUITE 0944

8725 J OHN J KINGMAN RD

FT BELVOIR VA 22060-6218

Telephone 18002253842

E-mail help@dtic.mil msorders@dtic.mil

WwW http://www.dtic.dla.mil/

All others may order reports through the National Technical Information Service:

NTIS

5285 PORT ROYAL RD

SPRINGFIELD VA 22161

Telephone 17034874650

17034874639 (TDD for the hearing-impaired)

E-mail_orders@ntis.fedworld.gov

WWW http://www.fedworld.gov/ntis/ntishome.html

A complete list of all CRREL technical publications is available from USACRREL (CECRL-LP)

72 LYME RD

HANOVER NH 03755-1290

Telephone 16036464338

E-mail techpubs@crrel.usace.army.mil

For information on all aspects of the Cold Regions Research and Engineering Laboratory, visit our World Wide Web site: http://www.crrel.usace.army.mil 


\section{CRREL Report 97-10}

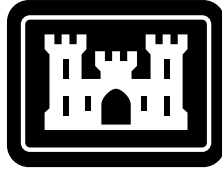

US Army Corps

of Engineers 8

Cold Regions Research \&

Engineering Laboratory

\section{A Review of Sintering in Seasonal Snow}

Samuel C. Colbeck 


\section{PREFACE}

This report was prepared by Dr. Samuel C. Colbeck, Senior Research Scientist, U.S. Army Cold Regions Research and Engineering Laboratory, Hanover, New Hampshire.

This work was supported at CRREL by DA Project 4A161102AT24, Work Package 127, Snow Properties and Processes, Work UnitSC-S01, Physical Properties of Snow Covers. The author benefited from the review of Dr. Jerome Johnson. The author thanks Dr. Edward Arons for pointing out the Zhang and Schneibel reference.

The contents of this report are not to be used for advertising or promotional purposes. Citation of brand names does not constitute an official endorsement or approval of the use of such commercial products. 


\section{CONTENTS}

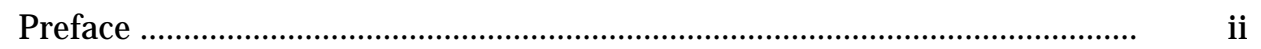

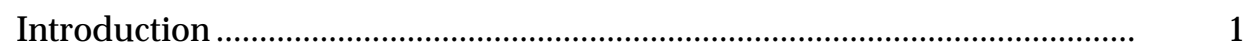

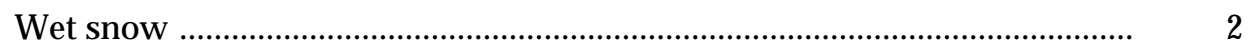

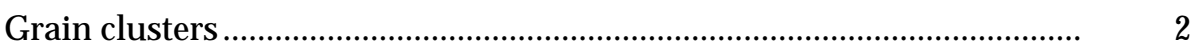

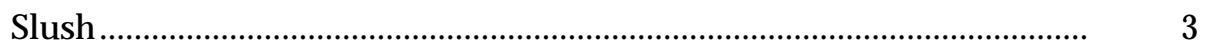

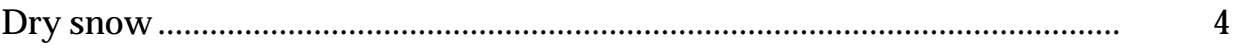

Rounded grains ……...........................................................................

Faceted grains ..................................................................................... 9

Discussion and conclusions ........................................................................ 9

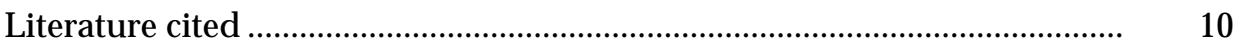

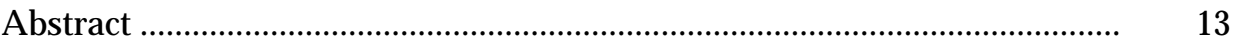

\section{ILLUSTRATIONS}

\section{Figure}

1. Cluster of ice grains in wet snow at a low liquid content .................... 2

2. Cross section of a three-grain cluster in wet snow ................................ 3

3. Slush, which consists of well-rounded grains 0.5 to $1 \mathrm{~mm}$ in size immersed in water

4. Geometry long assumed to describe rounded grains with necks in dry snow

5. Depth hoar, the extreme case of faceted crystals growing in dry snow at high growth rates due to large temperature gradients..... 4

6. Rounded grains, which grow at low growth rates in snow

7. Snow grains stored at $-24^{\circ} \mathrm{F}$ for several years showing distinct grain-boundary grooves at the bond

8. Fresh, dry snow with newly formed bonds showing a grainboundary with a grain boundary groove instead of reverse curvature

9. Equilibrium form of two grains of ice consisting of single crystals where the grain-boundary groove angle is $145^{\circ}$

10. Two idealized particles shown at an early and the final stages of sintering

11. End grain pointing downwards into the upward-moving stream of vapor 


\title{
A Review of Sintering in Seasonal Snow
}

\author{
SAMUEL C. COLBECK
}

\section{INTRODUCTION}

Snow on the ground consists of three basic components: air, ice grains, and liquid water when the snow is wet. Ice bonds form between the grains in most, but not all, types of snow. Much attention has been paid to the size, shape, and growth of the grains, but the bonds are of equal importance to the grains themselves, and relatively little attention has been paid to them. This probably occurs for two reasons. First, the bonds are smaller, partly hidden by the grains, and much harder to see with a hand lens. Second, the physics of their growth is not well understood, partly because their basic geometry is usually misunderstood. In fact, the literature describes sintering in snow as if the snow were a noncrystalline material with no imposed temperature gradient. The widely used approach to sintering in dry snow could be applied to glass beads held in an adiabatic cell, but not to ice grains in a seasonal snow cover.

When snow pits are dug to look for weak layers in the snow profile, the grains are generally examined rather than the bonds. For example, depth hoar is known to be weak due to poor bonding, so the existence of these highly faceted crystals is taken as evidence for the presence of a weak layer. In the International Classification System for Seasonal Snow on the Ground (Colbeck et al. 1990), there are photographs of the grains, but information about the bonds is only inferred. The size and shape of the grains are recorded in snow-pit logs, even when it is only the bonding that is of concern. Instead of direct examinations of the bonds, stereological methods have sometimes been used to infer information about the bonds, including their size and an assumed shape (e.g., Keeler 1969, Alley et al. 1982). Direct information about the degree of bonding comes from strength tests (e.g., Keeler 1969, Gow 1975), but these tests do not provide information about the geometry of the bonds nor about the processes that form them. Models describing the behavior of snow are often based on an assumed geometry or observations of the bonds from surface sections (e.g., Brown and Edens 1991.)

The strength of snow is not the only property that is controlled by the size of the bonds. Some properties depend primarily on the grains, such as the optical properties, where scattering and absorption can depend on grain size and shape. However, some properties are most sensitive to the narrow constrictions between grains where stresses are larger but heat and electrical flow paths are reduced. Thus the size, shape, and frequency of grain bonds greatly affects many of the most important properties of snow. Sintering is the process by which these bonds form and the study of their size, shape, and number density.

To study the bonds in snow, it must be recognized immediately that wet snow and dry snow are basically two different materials. While changes do occur more rapidly in wet snow because of the higher temperature, the fundamental difference is that the introduction of a third phase, liquid water, causes major reconfigurations of both grains and bonds. The geometries of wet and dry snow are markedly different, and their properties differ for several important reasons. Wet snow is active thermodynamically because of the high temperature and presence of the liquid phase, but vapor flow due to a macroscopic temperature gradient can only occur in dry snow.

Within each of these categories there are also two important divisions: wet snow at low and high liquid contents and dry snow at low and high growth rates. Wet snow is cohesionless and slushy at high liquid contents, but well-bonded at low liquid contents. Rapidly growing grains in dry snow lack bonding, whereas strong bonds form when the grains grow slowly. To understand the formation of bonds in snow, it is first 
necessary to understand the growth of the grains between which the bonds develop. Thus, for each category of snow, the growth of the grains is reviewed first to put the growth of the bonds in context. More details of the growth of grains in snow are given in an earlier review of the physics of snow metamorphism (Colbeck 1987a) and a more recent review from a more practical point of view (Colbeck, in press).

\section{WET SNOW}

Wet snow contains an observable quantity of liquid water in one of two basic modes of saturation. First, at low liquid contents where air is continuous throughout the pore space, the liquid is held by "grain clusters" in a mode of liquid saturation known as the "pendular regime." Second, at high liquid contents where the liquid is continuous throughout the pore space, the air occurs only in isolated bubbles trapped in the pores. This is "slush," where the liquid is in the "funicular regime" of saturation. The sintering of these two modes is markedly different because grain clusters develop strength quickly whereas slush is cohesionless. The first mode occurs when the snow is free to drain, while the second mode occurs in snow overlying a surface that impedes water flow.

\section{Grain clusters}

At low liquid contents, all of the liquid is held by capillarity in the crevices, veins, and junctions

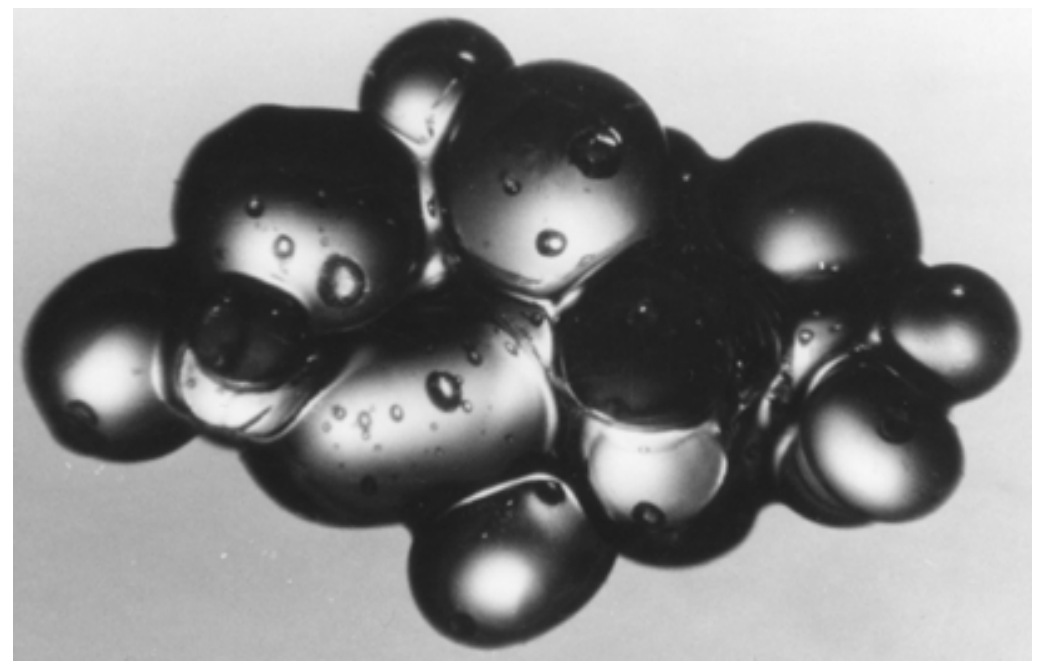

Figure 1. Cluster of ice grains in wet snow at a low liquid content. The individual ice grains are single crystals, usually 0.5 to $1.0 \mathrm{~mm}$ in size. of the clusters (see Fig. 1), and the remaining pore space is filled with air. The basic unit of a cluster is the well-rounded single crystal of ice: the grain, or the minimum observable unit. These single crystals join in groups of two or more and are tightly bonded by ice-to-ice contacts, not by capillarity as is often supposed; the ice-to-ice grain boundaries are depicted in Figure 2 for a threegrain cluster. Their large size gives the snow considerable strength. The liquid-filled veins form at the junctions of three crystals, and more water is held at the junctions of four veins. The geometry of these veins and junctions can be most easily visualized by examining the lines joining soap bubbles that have had time to grow to a size of about $10 \mathrm{~mm}$.

While the growth of individual grains at low liquid contents is not as rapid as grain growth in slush, the clusters do form rapidly by the collecting together of existing grains into clusters. Fully developed clusters arise from drained slush in about 24 hours, which is remarkably fast compared with the growth of particles by any other process in snow. This happens in part because the clusters are at the melting temperature and thus transport through the liquid phase is possible. As a result, vapor diffusion is probably not the ratelimiting process that it is in grain growth in dry snow. Of course, these clusters are multicrystalline collections, so their growth processes are different from the processes that lead to the growth of grains of single crystals.

Clusters form in this manner because this configuration of the vapor/ice, vapor/water, and ice/ water interfaces minimizes the total surface free energy (Colbeck 1979a). Neighboring clusters are well bonded to each other, with ice-to-ice bonds forming between two grains, one ice grain from each cluster. These ice-to-ice bonds are strong enough to give this form of snow some considerable strength, both within the clusters and within the snow cover as a whole. In fact the strength is well-known to vary significantly with the liquidwater content of snow (Kinosita 1963, Colbeck 1979b).

Another form of well-bonded snow is also common, one that forms a transition between the categories of wet and dry snow. Amorphous, multicrystalline par- 


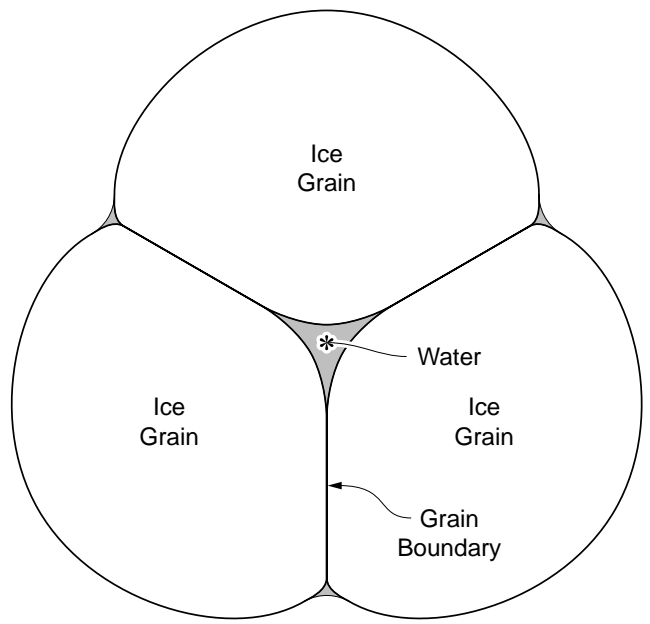

Figure 2. Cross section of a three-grain cluster in wet snow. Liquid is held in the crevices between two grains, the veins among three grains, and the junctions that join four veins. Air fills the remaining pore space.

ticles arise from melt-freeze cycles, simply by the freezing together of individual grains. When this happens, it destroys the granular geometry of the grain cluster but probably increases the strength of the snow cover. These particles are also icebonded to their neighbors.

\section{Slush}

At higher liquid contents, the air is no longer continuous throughout the pore space, but is limited to isolated air bubbles trapped by constrictions in the pores. Since these bubbles occupy the largest part of the pore space, the volumetric air content can still be higher than the volumetric liquid content, but only the liquid phase is mobile. In fact, the permeability to the liquid increases with liquid content, and slush is highly capable of conducting liquid water. In addition,

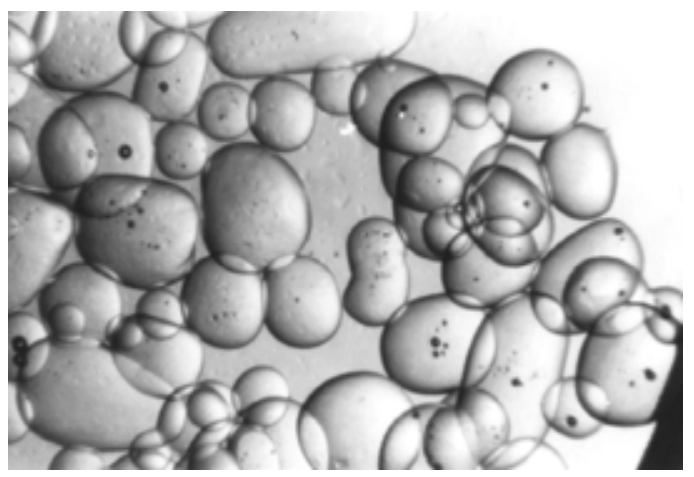

Figure 3. Slush, which consists of well-rounded grains 0.5 to $1 \mathrm{~mm}$ in size immersed in water. These do not bond, and therefore slush lacks cohesion.

since the ice grains are surrounded by water (see Fig. 3), grain growth in slush is very rapid as first measured by Wakahama (1968) and later explained by Colbeck (1987b). Slush lacks intergranular bonding as do rapidly growing grains in dry snow, but for very different reasons. In slush, the bonds are unstable because, when stressed, they melt away by pressure melting, whereas with clusters, the ice-to-ice bonds are stable against pressure melting even though the snow contains liquid water (Colbeck 1979a). This is a very fundamental difference between the pendular and funicular regimes of water contents since it leads directly to high strength at low liquid contents and low strength at high liquid contents. This fundamental difference in the thermodynamics is due to the basic differences in the geometry.

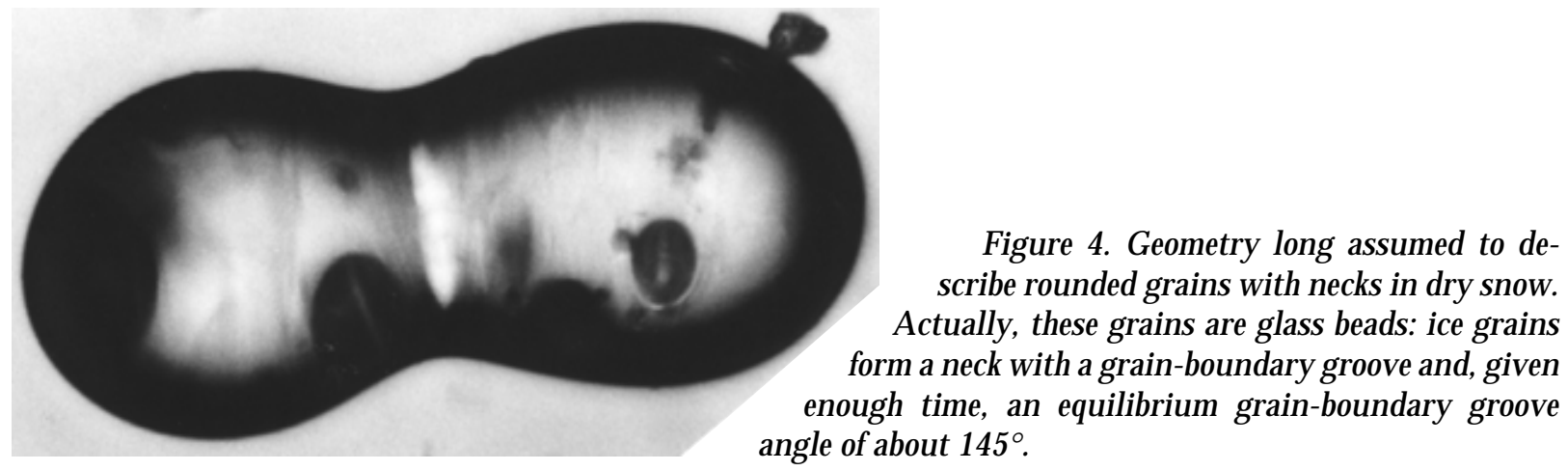




\section{DRY SNOW}

The most studied case of sintering in snow is that of well-rounded grains in dry snow where the grains grow slowly while they build intergranular bonds (e.g., Kingery 1960, Kuroiwa 1962, Hobbs and Mason 1964). The bonds have long been described as necks with a concave geometry (see Fig. 4) where the growth of the bonds is driven by vapor pressure differences over the convex (grain) and concave (bond) surfaces. Although this assumption about the geometry is supported by few observations, it is common to assume this geometry in the sintering of many materials (e.g., Swinkels and Ashby 1981, Moya et al. 1987, Lenel 1992). Figure 4 shows that it is the appropriate geometry for a noncrystalline material, but this geometry would not seem possible for a crystalline material because, at least at slow rates of growth, the equilibrium form of the crystal must evolve, and that requires the presence of a grainboundary groove at the crystalline boundary.

The rapid growth of faceted grains, depth hoar being the extreme form (see Fig. 5), is of equal interest to the case of the slower-growing rounded grains. When rapid growth occurs, the rounded grains are consumed, leaving poorly bonded, faceted grains that do not sinter rapidly because of their large size and because their rapid growth leaves little time for sintering. They do sinter once the rapid growth slows, but they sinter slowly because of their large size. I know of no direct observations of the bonds formed during rapid

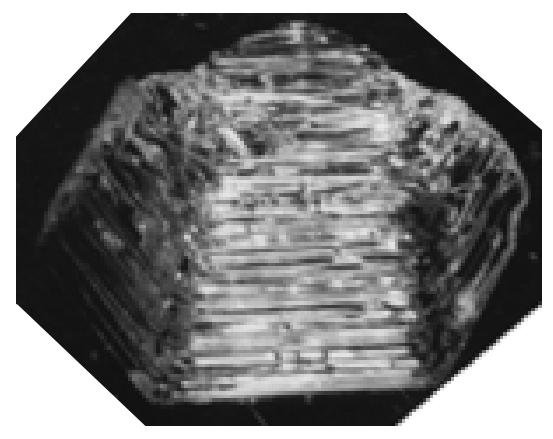

Figure 5. Depth hoar, the extreme case of faceted crystals growing in dry snow at high growth rates due to large temperature gradients. These are poorly sintered because their formation consumes the well-sintered, rounded grains, and large grains sinter slowly. growth of snow grains, although Sturm (1991) has observed the various stages of the growth of depth hoar.

\section{Rounded grains}

Rounded grains grow in dry snow at high densities and/or low temperature gradients in the snow cover. Figure 6 shows a bond between two rounded grains that are the "equilibrium form" of the ice crystal (Colbeck 1983a). This photograph was taken to show the grains, not the bond, and thus the bond is not fully visible in the photograph. However, the grain-boundary groove is visible along with a feature that I have observed in all of my laboratory observations of the growth of bonds between grains: one of the ice grains reshapes itself to form an elongated neck at the contact but the other grain retains a much more sphere-like shape adjacent to the contact. Thus, a distinct dissymmetry tends to develop at the contact, probably due to the different crystallographic orientations of the two crystals.

The growth process for all types of snow grains in dry snow was described by Yosida et al. (1955) as "the hand-to-hand delivery of water vapor" because water vapor migrates through the snow cover from the warmer part to the colder part, which is usually from the lower layers to the upper. It does so by the step-by-step conveyance of water from each ice grain to its coldest neighbor. This process enhances the rate of vapor diffusion for two reasons. First, the vapor diffuses across the pores only, so the flow path is short-

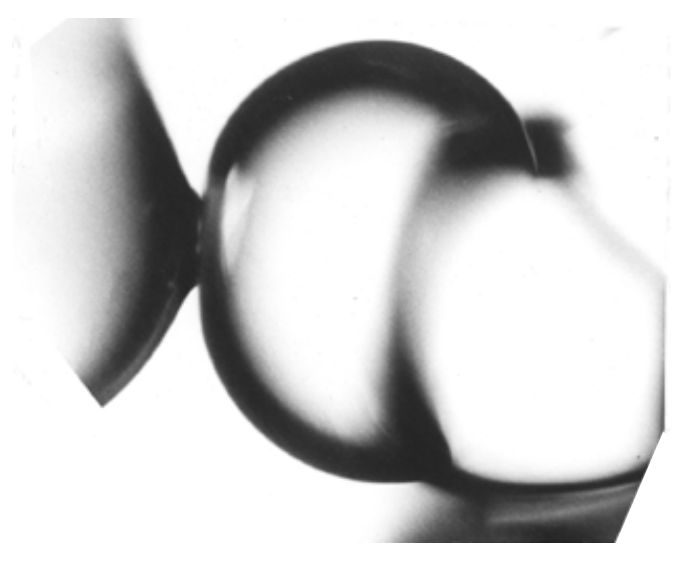

Figure 6. Rounded grains, which grow at low growth rates in snow. They sinter, giving the snow a slab strength. This shows a newly formed bond with a sharp grain boundary groove angle. The neck on one grain only is not uncommon. 
ened. Second, the temperature difference across the pores is increased, since the thermal conductivity is much higher for ice than for air. For these reasons the coefficient of diffusion of water vapor in snow is much higher than it is in air. This grainto-grain movement of water vapor was described by Colbeck (1983b) using temperature differences among the grains, and this theory was further developed by Gubler (1985) to include the dynamics of a population of grains.

A "slab" strength develops simultaneously with the growth of rounded grains, especially when deposition of the snow layer is accompanied by high winds. Ideas from other materials have been applied to describe the formation of the bonds that provide that strength. It has long been assumed that the bonds, or necks, have a reverse or concave geometry that causes the migration of water molecules to the neck by sublimation, surface diffusion, surface flow, volume diffusion, plastic flow, and/or grain boundary diffusion. Kuczynski (1949) pioneered the classical approach to the physics of sintering. His basic idea was that different mechanisms occurred at different characteristic rates and that the dominant mechanism could be determined from the rate. This result is often summarized by the equation

$$
\left(\frac{x}{R}\right)^{n}=\frac{f(T)}{R^{m}}
$$

where $x$ is the radius of the neck, $R$ is the radius of the grain, $f(T)$ is a function of temperature $(T)$, and $t$ is time. The constants, $m$ and $n$, assume different values for different processes and are determined from the appropriate experimental observations of sintering.

This approach was promoted and extended by Kingery (1960), who first applied it to ice. Kingery concluded that the welding together of pieces of ice at subfreezing temperatures was due to surface diffusion, an idea that has not received wide support. By direct observation, he found that the rate of neck growth, when normalized to grain size, was proportional to $t^{1 / 6.9}$. The rate of sintering was much more rapid for smaller grains, in accordance with eq 1. Unfortunately, his observations do not allow a close examination of the geometry of the neck, which could provide some insight into the processes. Thus, his conclusion about the role of surface diffusion was based on the time-dependence of the experimental results and the fact that theory shows that sublimation could not happen fast enough to account for the observed rate. However, the coefficient of surface diffusion required was very high and the temperature dependence was large, but this might be due to changing surface structure as the melting temperature is approached.

It is tempting to account for rapid surface diffusion by assuming a liquid-like or a liquid layer on the surface of ice, at least at higher temperatures (Dash et al. 1995, Petrenko 1994), but this idea must still be put in a convincing, quantitative form. Gubler (1982) has laid out this problem but left the following concerns: First, he assumed the usual reverse curvature for the geometry of the bond, but there is very little evidence that this is the correct geometry. Second, the viscosity and thickness of the surface layer are critical, but controversial. Much remains to be learned about the surface of ice before this can be resolved. For example, the rate is very sensitive to the humidity (Hosler et al. 1957), which is not surprising since the structure of an ice surface can change visibly with changes in humidity.

Kuroiwa (1962) examined the grain bonds using Kuczynski's (1949) basic ideas about the processes. He concluded that volume diffusion was the dominant process when air filled the pore space and found that the rate of sintering was much lower when the air was displaced by kerosene. It is disappointing that Kuroiwa missed an apparent conclusion from his own figures, even if they were made from thin sections: they show grain-boundary grooves, not the concave geometry normally assumed (Fig. 4). Even most of the more recent thinking about sintering still assumes this concave geometry (Swinkels and Ashby 1981), but sintering with grain-boundary grooves has been at least partly described (Zhang and Schneibel 1995). It is important to realize that, since a grain-boundary groove is present, replacing air with another fluid will change the dihedral angle at the groove. It could also change the surface structure of ice and its surface energy. Thus, we should expect the rate of sintering to change, even if the dominant process stays the same.

Hobbs and Mason (1964) rejected the approach of the metallurgists and ceramists, stating that it could not be applied to ice. Instead, they believed that sublimation, transfer through the vapor phase, had to be the dominant mechanism, and Ramseier and Keeler (1967) supported this conclusion with strength tests of snow with either air or oil in the pore space. Hobbs and Mason did leave open the question of the mechanism(s) during the initial 

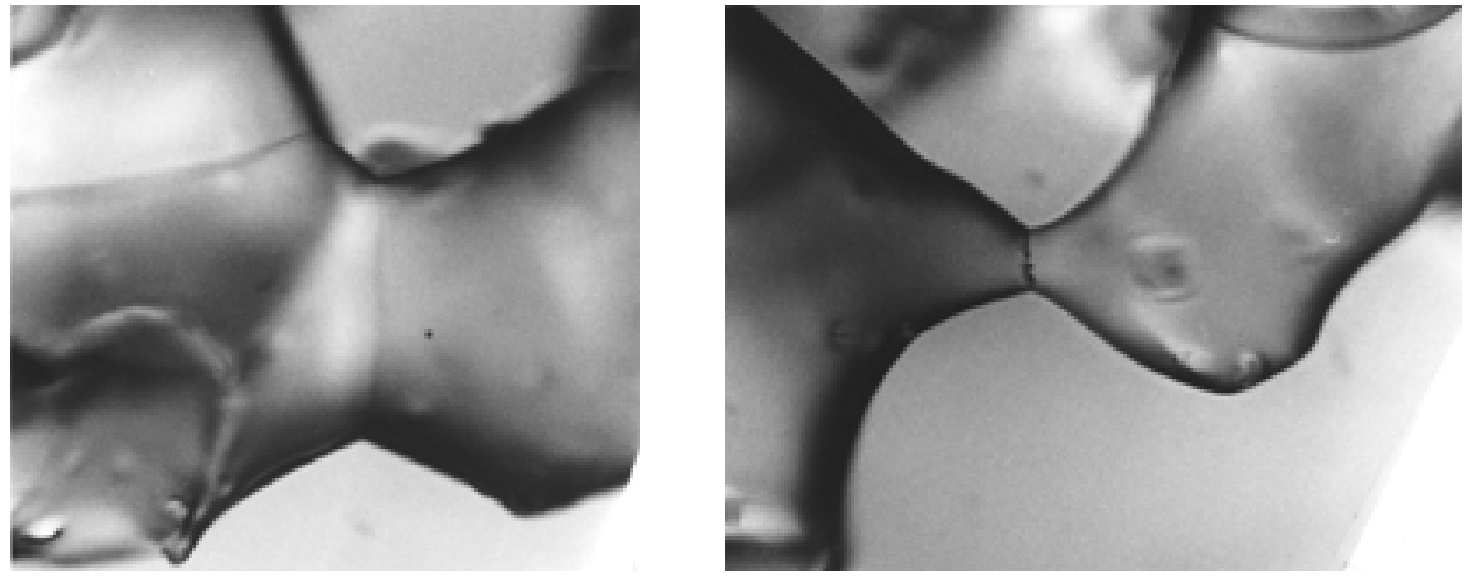

Figure 7. Snow grains stored at $-24^{\circ} \mathrm{F}$ for several years showing distinct grain-boundary grooves at the bonds.

period of the formation of a bond when surface diffusion, or even pressure melting-regelation, could occur. In fact, it makes a lot of sense to think about different mechanisms dominating during different phases of bond growth, just as Alley et al. (1982) and Wilkinson (1988) did for densification. Ideas based on a concave curvature (Fig. 4) could dominate during the early phases when sintering is most rapid, and microphotographs are not yet available to disprove the notion of a simple concave bond. Figure 6 shows that one grain can be purely convex while the other has mixed curvature, and thus different processes may operate on adjacent grains, or even on different parts of one grain. Figure 7 shows the nature of grain bonds in snow stored at a low temperature for several years: these bonds are crystal boundaries with grain-boundary grooves and the appropriate grain-boundary groove angle for ice and water vapor, about $145^{\circ} \pm 2^{\circ}$ (Ketcham and Hobbs 1969). Because the grains are not packed in a regular manner, part of the grain surface can be still be concave, even at this late stage of sintering.

The formation of grain-boundary grooves is not limited to old snow that has had a long time to reach its equilibrium form. A fresh snow bond of a similar nature is shown in Figure 8. In fresh snow, the grain-boundary groove angle appears to be much less than the equilibrium value of $145^{\circ}$ because the bonds have just formed. The bond grows rapidly at first as the stress imbalance at the junction is reduced, probably with an exponential decay. Kuroiwa's (1962) photographs and my own microscopic observations suggest to me that the dihedral angle increases with time of sintering. However, his photographs can be mis- leading in this regard since they where made from sections and not from the whole grains. As discussed later, it is important to know if the dihedral angle of about $145^{\circ}$ is always maintained throughout sintering, or if the angle is small initially and then increases as sintering proceeds. This question should be answered with more microscopic observations, since its answer will determine how we think about the processes and how they are modeled. For example, if an angle of about $145^{\circ}$ is always maintained, there will necessarily be concave curvature adjacent to the grainboundary groove, at least during the initial stage of sintering. This will affect all of the processes, regardless of what they are.

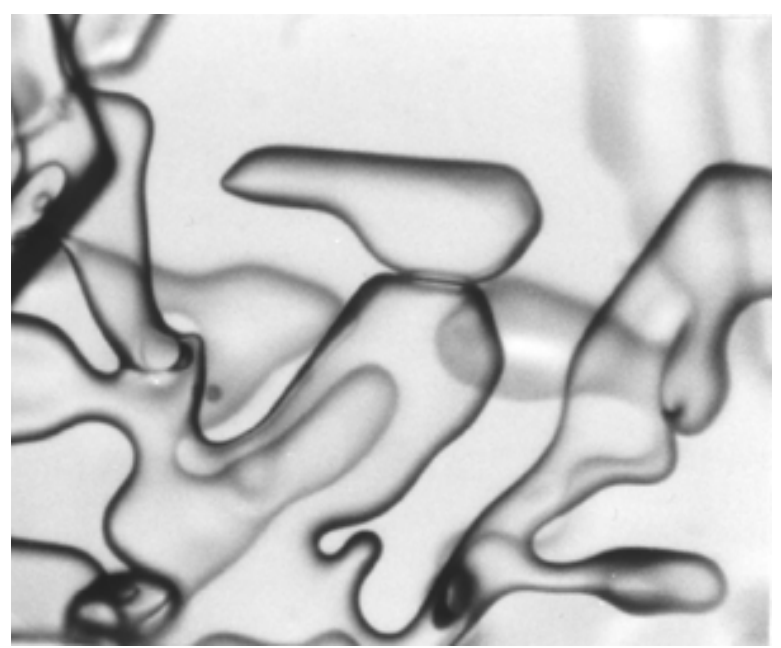

Figure 8. Fresh, dry snow with newly formed bonds showing a grain boundary with a grain-boundary groove instead of reverse curvature. 


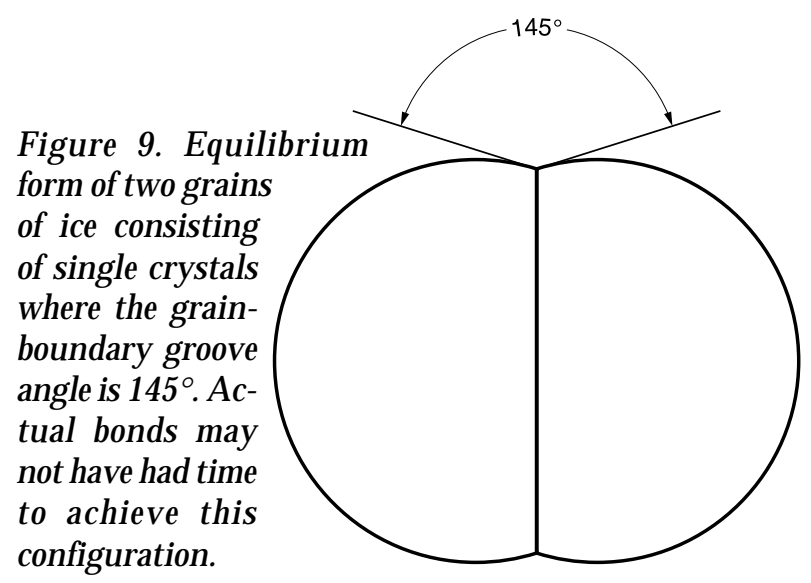

Keeler (1969) found that the rate of bond growth was much greater in natural snow than predicted by sintering theory. Although he attributed this to stresses in the snow, the effect of stress on the thermodynamics is very small and thus it seems likely to me that this is due to the presence of a macroscopic temperature gradient. These are always imposed on the snow cover by environmental factors, and thus water vapor is driven through the snow. This enhanced vapor movement should be much greater than vapor movement due to differences in curvature or stress. A much greater rate of vapor flow should cause faster bond growth, just as it causes faster grain growth (Colbeck 1983b). While the bonds must move toward their equilibrium shape, the rate at which the bonds grow is probably controlled by vapordensity gradients caused by macroscopic temperature gradients, not by microscopic curvature or stress differences. Without an imposed temperature gradient, depth hoar could not grow at all in snow, and rounded crystals would grow much more slowly than observed (de Quervain 1958). Given that the rate-limiting factor in mass flow in snow is the vapor density gradient, which is controlled by the temperature profile, the classical theory of sintering may have little to do with the rate of formation of bonds in dry snow. This probably explains why the rate of sintering has often been found to occur faster than is described by models or laboratory experiments.

The basic geometries of rounded grains and their bonds are controlled by phase equilibrium. Thus, the shape of the bond, but not its rate of growth, can only be understood by examination of the equilibrium condition at the bond. Ice grains in dry snow generally consist of single crystals, so the bonds must be simple grain boundaries with grain-boundary grooves. Kuroiwa's (1962) Figure 9 shows bonding between polycrystalline grains, but the actual bond appears to connect only two of the crystals, one within each grain.

When two ice grains consisting of a single crystal each are joined by a bond, the equilibrium form of the arrangement should be as shown in Figure 9. For the old grains shown in Figure $7 \mathrm{~b}$, the grain-boundary groove angles are about $138^{\circ}$ and $148^{\circ}$, close to the equilibrium value observed by Ketcham and Hobbs (1969). For the fresh snow shown in Figure 8, the grain-boundary groove angle appears to be much smaller because the bond has not yet had sufficient time to approach the equilibrium condition. However, a closer examination of this bond could prove that the actual angle is closer to the equilibrium value.

Zhang and Schneibel (1995) described the sintering of grains joined by grain-boundary grooves. They explained the imbalance of forces that occurs in the grain-boundary groove before the equilibrium condition has been established; they assumed that the dihedral angle was fixed throughout the process. Sintering in their model was limited to grain boundary and surface diffusion and expressing their results in terms of the diffusivity ratio of these two processes. Unfortunately, the values for the diffusivities are still uncertain for ice, so it is not possible to calculate meaningful rates of bond growth based on these processes. Furthermore, in seasonal snow covers it seems likely that the shape is determined by the requirement for equilibrium, but the rate is determined by vapor flux due to the macroscopic temperature gradient. In spite of these limitations, the ideas expressed by Zhang and Schneibel (1995) are clearly applicable to sintering in snow and, if fact, are vital to understanding what is actually observed in snow. For this reason their work on surface and grain-boundary diffusion is summarized here.

Surface diffusion is proportional to the gradient of the chemical potential, or the gradient of curvature along the surface. As the resulting flux reconfigures the surface, the growth or decay of the surface is given by the gradient of the flux, so

$$
\frac{\partial r_{\mathrm{a}}}{\partial t}=B \frac{\partial^{2} K}{\partial s^{2}}
$$

where $r_{\mathrm{a}}$ is the normal vector to the surface, $K$ is the surface curvature, which is positive for convex surfaces, $s$ is length along the surface, and 


$$
B=\frac{\delta_{\mathrm{s}} D_{\mathrm{s}} \gamma \Omega}{\mathrm{k} T}
$$

where $\delta_{\mathrm{s}}=$ the surface diffusive width,

$D_{\mathrm{s}}=$ the coefficient of surface diffusion

$\gamma=$ the surface free energy for the solidvapor surface

$\Omega=$ the atomic volume

$\mathrm{k}=$ Boltzmann's constant.

The surface flux is then taken as

$$
J_{\mathrm{s}}=\frac{\delta_{\mathrm{s}} D_{\mathrm{s}} \gamma}{\mathrm{k} T} \frac{\partial K}{\partial \mathrm{s}} .
$$

Zhang and Schneibel (1995) assumed a straight grain boundary from which parallel layers of matter are removed during sintering. These molecules diffuse away by flux along the grain boundary, a flux that arises from the stress gradient along the boundary. The flux is given by

$$
J_{\mathrm{b}}=\frac{\delta_{\mathrm{b}} D_{\mathrm{b}} \gamma}{\mathrm{k} T} \frac{d \sigma}{d y}
$$

where the subscript $b$ refers to the grain boundary, $\sigma$ is the normal stress acting across the grain boundary, and $y$ is the radial distance across the boundary. The normal stress at the base of the grain-boundary groove due to the pull of the vapor-ice surfaces is $-\gamma K_{0}$, where $K_{0}$ is the curva- ture at the base of the grain-boundary groove. The stress along the grain boundary is easily derived with that end condition and requires that $K Y$ equal $\sin (A / 2)$ at the base of the groove when equilibrium is established and the flux disappears. Thus, the theory requires that equilibrium can only be achieved when the curvature is the same everywhere. This does ignore crystallographic differences between the two grains, differences that clearly arise when two ice grains are observed to sinter, but for now we will have to accept this limitation.

When material is removed from the grain boundary by grain-boundary diffusion and moves onto the free surfaces of the two grains by surface diffusion, the fluxes are in balance when, at the base of the groove,

$$
J_{\mathrm{b}}=2 J_{\mathrm{s}} \text {. }
$$

Zhang and Schneibel (1995) used this and two other conditions to describe the changing geometry as two particles grow in size and move closer. They do so until the two grains achieve the final condition, capped spheres, as shown in Figure 10. The two other conditions are that the dihedral angle remain constant and that the base of the groove move outward, as shown in Figure 10.

In their numerical calculations they used the ratio of the grain boundary and surface diffusivities, $\Gamma$, where

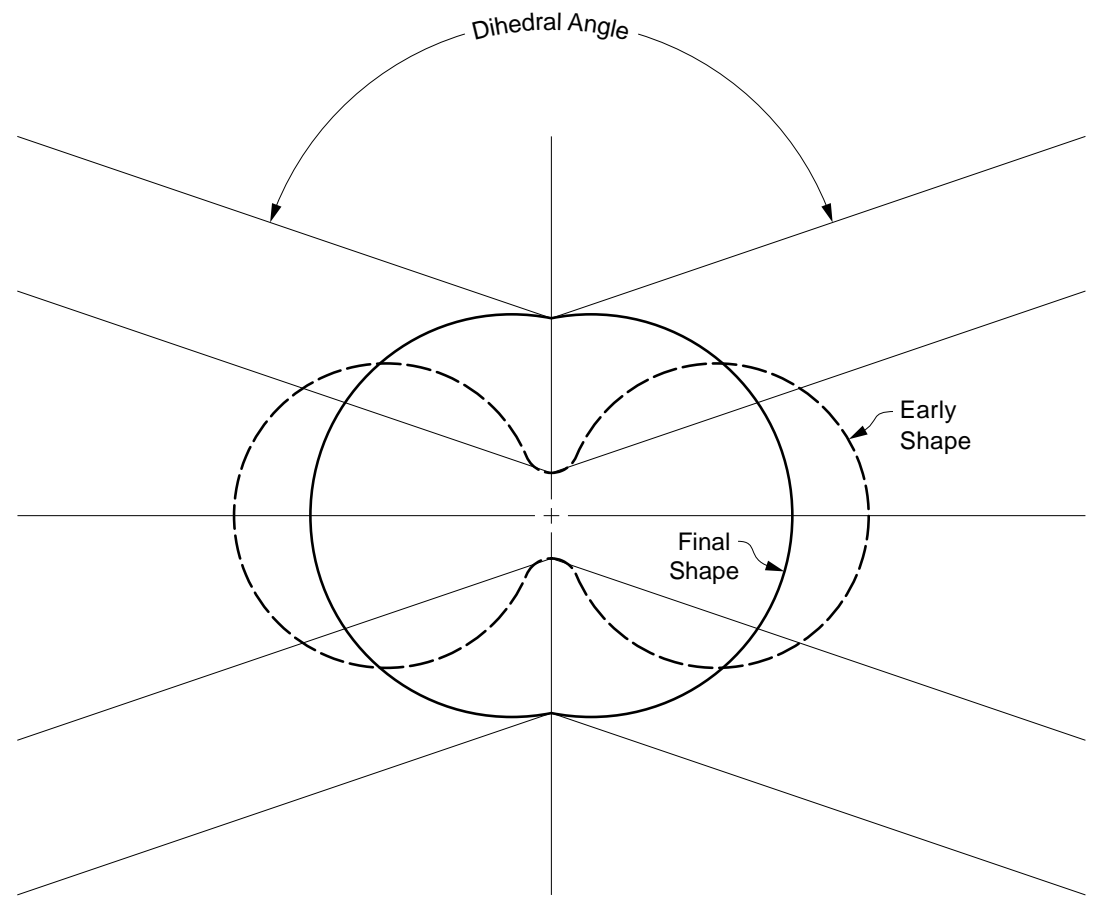

Figure 10. Two idealized particles shown at an early and the final stages of sintering. The dihedral angle is maintained at a constant value throughout sintering in this example. However, it appears that the dihedral angle changes during sintering of ice grains. (After Zhang and Schneibel 1995.) 


$$
\Gamma=\frac{D_{\mathrm{b}} \delta_{\mathrm{b}}}{D_{\mathrm{s}} \delta_{\mathrm{s}}} .
$$

They found, for example, for a dihedral angle of $150^{\circ}$, that the time to reach $50 \%$ of the final neck shape decreased as $\log (\Gamma)$ increased. Thus, for each order-of-magnitude increase in grain-boundary diffusivity, there is an increase of a factor of two to five in the rate of sintering due to the removal of material from the grain boundary and deposition of that material on the free surfaces.

While this theory ignores sublimation, crystallographic differences, and the role of the macroscopic temperature gradient in determining the rate of sintering, at least it includes the role of the dihedral angle and grain-boundary diffusion. Perhaps its greatest limitations are the assumptions of a constant dihedral angle and an adiabatic environment.

\section{Faceted grains}

Faceted grains grow rapidly due to high temperature gradients and low densities. They have long been of interest because they are associated with low strength and avalanche release. In 1973, de Quervain proposed that grains situated at specific sites would preferentially grow more rapidly. This includes "end grains" that are not connected at their lower end and thus point downward into the upward-moving stream of vapor being driven by the temperature gradient (Fig. 11). Without being connected at their lower ends, they grow rapidly, especially if there is a large distance between the end grain and the grain below it. Furthermore, because they are not connected at the bottom, they fail to form a bond there. This is one reason why, during a major recrystallization, where the rounded grains are replaced by faceted grains, the bond density of the new grains is low compared with that of the

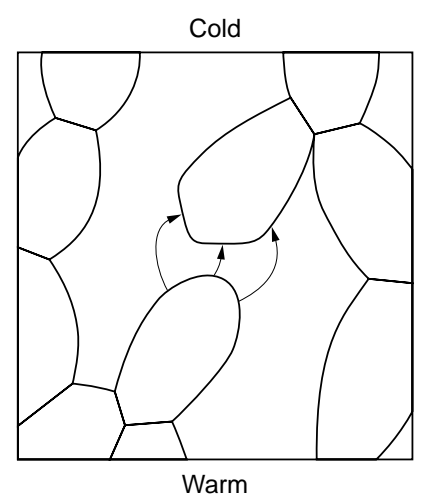

Figure 11. End grain pointing downwards into the upward-moving stream of vapor as suggested by de Quervain (1973). old grains. Direct observations of bond growth rate and geometry are needed during their growth.

\section{DISCUSSION AND CONCLUSIONS}

There is a fundamental difference between wet and dry snow since liquid water causes major reconfigurations of both grains and bonds. Within the wet and dry snow categories there are also two important divisions: wet snow at low and high liquid contents and dry snow at low and high growth rates. Wet snow is cohesionless and slushy at high liquid contents because the grain boundaries are unstable against pressure melting. However, wet snow is well-bonded at low liquid contents where ice-bonded clusters form. A transitional form of snow, melt-freeze grains, can be either wet or dry. These amorphous, multicrystalline particles arise from melt-freeze cycles. They are solid within and well-bonded to their neighbors.

Rapidly growing grains in dry snow lack bonding because they consume the existing grains, they are large, and they grow rapidly. However, strong bonds form among rounded grains, and they grow slowly. Their growth processes and geometry have probably been misunderstood, even though this is the most studied case of sintering in snow. The bonds are usually described as necks with a concave geometry as in most studies of sintering of other materials. However, this geometry would not seem possible for a crystalline material because the equilibrium form of the crystal requires the presence of a grain-boundary groove at the crystalline boundary.

In the past it has been assumed that the reverse geometry causes the migration of water molecules to the neck by one of many possible processes; the dominant mechanisms were identified by the observed dependence on time. Kingery (1960) first applied this approach to ice; he concluded that the bonding was due to surface diffusion. However, the coefficient of surface diffusion required was very high, and although this might be explained by a highly mobile surface layer, this idea remains to be convincingly demonstrated.

Kuroiwa (1962) concluded that volume diffusion was the dominant process, but Hobbs and Mason (1964) believed that sublimation, transfer through the vapor phase, had to be the dominant mechanism. The vapor transfer mechanism has since received wide support and was supported by the strength tests of Ramseier and Keeler (1967). 
In fact, various mechanisms may dominate under different conditions or even during different stages of sintering under given conditions. Mechanisms based on the concave curvature could dominate during the early phases when sintering is most rapid, because microphotographs are not yet available to disprove the notion of a concave bond for all stages of sintering. However, the classical concepts based on concave curvature cannot dominate after the grain-boundary groove is established, which could be at the instant that contact is made. The grain-boundary groove angle in the bond at equilibrium is about $145^{\circ}$ but, in fresh snow the angle appears to be much smaller because the bonds have just formed. The bond grows rapidly at first due to the stress imbalance at the junction, but the growth rate decreases rapidly with time.

Keeler (1969) found a higher rate of bond growth in natural snow than expected from laboratory experiments. This is almost certainly due to the temperature gradients that occur in nature but were absent in the laboratory experiments. These gradients cause vapor movement at a much greater rate than could occur just due to differences in curvature or stress. Since the ratelimiting factor in mass flow in snow is probably the vapor density gradient, which is controlled by the temperature profile, the classical theory of sintering may have little to do with the rate of formation of bonds in dry snow.

Zhang and Schneibel (1995) described the sintering of grains joined by grain-boundary grooves based on the imbalance of forces that occurs in the grain-boundary groove before the equilibrium condition has been established. If new bonds assume a very small angle between the ice grains, this would cause a large grain-boundary drag, which would lead to continuous reconfiguration until the equilibrium condition is established. Zhang and Schneibel (1995) modeled grain-boundary growth due to grain boundary and surface diffusion, expressing their results in terms of the diffusivity ratio of these two processes. Unfortunately, the values for the diffusivities are still uncertain for ice, so it is not possible to calculate meaningful rates of bond growth based on these processes. Furthermore, in seasonal snow covers it seems likely that the shape is determined by the requirement for equilibrium, but the rate is determined by vapor flux due to the macroscopic temperature gradient.

\section{LITERATURE CITED}

Alley, R.B., J.F. Bolzan, and I.W. Whillans (1982) Polar firn densification and grain growth. Annals of Glaciology, 3: 7-11.

Brown, R.L., and M.Q. Edens (1991) On the relationship between neck length and bond radius during compression of snow. Journal of Glaciology, 37: 203-208.

Colbeck, S.C. (1979a) Grain clusters in wet snow. Journal of Colloid and Interface Science, 72, 371-384. Colbeck, S.C. (1979b) Sintering and compaction of wet snow. Philosophical Magazine, 39: 13-32.

Colbeck, S.C. (1983a) Ice crystal morphology and growth rates at low supersaturations and high temperatures. Journal of Applied Physics, 54: 26772682.

Colbeck, S.C. (1983b) Theory of metamorphism of dry snow. Journal of Geophysical Research, 88: 5475-5482.

Colbeck, S.C. (1987a) A review of the metamorphism and classification of seasonal snow cover crystals. In Avalanche Formation, Movement and Effects (S.C. Colbeck, Ed.). International Association of Hydrological Science, vol. 162, p. 1-34.

Colbeck, S.C. (1987b) Theory of particle coarsening with a log-normal distribution. Acta Metallurgica, 35(7): 1583-1588.

Colbeck, S.C. (in press) The basic ideas behind snow metamorphism. In Snow as a Physical, Ecological and Economic Factor, Davos, Switzerland, 1996. Colbeck, S., E. Akitaya, R. Armstrong, H. Gubler, J. Lafeuille, K. Lied, D. McClung, and E. Morris (1990) The International Classification for Seasonal Snow on the Ground. The International Commission on Snow and Ice of the International Association of Scientific Hydrology (available from World Data Center, University of Colorado, Boulder, Colo.). Dash, J.G., H. Fu, and J.S. Wettlaufer (1995) The premelting of ice and its environmental consequences. Reports on Progress in Physics, 58: 115-167.

de Quervain, M.R. (1958) On metamorphism and hardening of snow under constant pressure and temperature gradient. In International Association of Scientific Hydrology (M.R. de Quervain, Ed.). Publication 46, p. 225-239.

de Quervain, M.R. (1973) Snow structure, heat and mass flux through snow. International Association of Scientific Hydrology, p. 203-226.

Gow, A.J. (1975) Time-temperature dependence of sintering in perennial isothermal snowpacks. In Snow Mechanics. International Association of 
Hydrological Sciences, IAHS-AISH, vol. 114, p. 25-41.

Gubler, H. (1982) Strength of bonds between ice grains after short contact times. Journal of Glaciology, 28: 457-473.

Gubler, H. (1985) Model of dry snow metamorphism by interparticle vapor fluxes. Journal of Geophysical Research, 90: 8081-8092.

Hobbs, P.V., and B.J. Mason (1964) The sintering and adhesion of ice. Philosophical Magazine, 9: 181-197.

Hosler, C.L., D.C. Jensen, and L. Goldshlak (1957) On the aggregation of ice crystals to form snow. Journal of Meteorology, 14: 415-420.

Keeler, C.M. (1969) The growth of bonds and the increase of mechanical strength in a dry seasonal snow-pack. Journal of Glaciology, 8: 441-450.

Ketcham, W.M., and P.V. Hobbs (1969) An experimental determination of the surface energies of ice. Philosophical Magazine, 19: 1161-1173.

Kingery, W.D. (1960) Regelation, surface diffusion, and ice sintering. Journal of Applied Physics, 31: 833-838.

Kinosita, S. (1963) Compression of snow immersed in water of $0^{\circ} \mathrm{C}$. Low Temperature Science, A21: 13-22.

Kuczynski, G.C. (1949) Self-diffusion in sintering of metallic particles. Journal of Metals, 1: 169-178.

Kuroiwa, D. (1962) A study of ice sintering. USA Cold Regions Research and Engineering Laboratory, Research Report 86.

Lenel, F.V. (1992) Sintering. In McGraw-Hill Encyclopedia of Science and Technology (F.V. Lenel, Ed.). New York: McGraw-Hill, vol. 16, p. 461-462.
Moya, J. S., C. Baudin, and P. Miranzo (1987) Sintering. In Encyclopedia of Physical Science and Technology (J.S. Moya, C. Baudin, and P. Miranzo, Eds.). Orlando, Florida: Academic Press, vol. 12, p. 699-712.

Petrenko, V.F. (1994) The surface of ice. USA Cold Regions Research and Engineering Laboratory, Special Report 94-22.

Ramseier, R.O., and C.M. Keeler (1967) The sintering process in snow. USA Cold Regions Research and Engineering Laboratory, Research Report 226.

Sturm, M.A. (1991) The role of thermal convection in heat and mass transport in the subarctic snow. USA Cold Regions Research and Engineering Laboratory, CRREL Report 91-19.

Swinkels, F.B., and M.F. Ashby (1981) A second report on sinter diagrams. Acta Metallurgica, 29: 259-281.

Wakahama, G. (1968) The metamorphism of wet snow. IUGG General Assembly of Bern, September-October 1967. International Association of Scientific Hydrology, p. 370-379.

Wilkinson, D.S. (1988) Pressure-sintering model for the densification of polar firn and glacier ice. Journal of Glaciology, 34: 40-45.

Yosida, Z., and colleagues (1955) Physical studies on deposited snow. I. Thermal properties. Low Temperature Science, 7: 19-74.

Zhang, W., and J. H. Schneibel (1995) The sintering of two particles by surface and grain boundary diffusion-a two-dimensional numerical study. Acta Metallurgica and Materiallia, 43: 43774386 . 
Public reporting burden for this collection of information is estimated to average 1 hour per response, including the time for reviewing instructions, searching existing data sources, gathering an maintaining the data needed, and completing and reviewing the collection of information. Send comments regarding this burden estimate or any other aspect of this collection of information, including suggestion for reducing this burden, to Washington Headquarters Services, Directorate for Information Operations and Reports, 1215 Jefferson Davis Highway, Suite 1204, Arlington, VA 22202-4302, and to the Office of Management and Budget, Paperwork Reduction Project (0704-0188), Washington, DC 20503.

\begin{tabular}{|l|l|l}
\hline 1. AGENCY USE ONLY (Leave blank) & $\begin{array}{l}\text { 2. REPORT DATE } \\
\text { December } 1997\end{array}$ & 3. REPORT TYPE AND DATES COVERED \\
\hline
\end{tabular}

4. TITLE AND SUBTITLE

5. FUNDING NUMBERS

A Review of Sintering in Seasonal Snow

6. AUTHORS

PR: 4A161102AT24

Samuel C. Colbeck

WP: 127

WU: SC-S01

7. PERFORMING ORGANIZATION NAME(S) AND ADDRESS(ES)

8. PERFORMING ORGANIZATION

REPORT NUMBER

U.S. Army Cold Regions Research and Engineering Laboratory

72 Lyme Road

CRREL Report 97-10

Hanover, New Hampshire 03755-1290

9. SPONSORING/MONITORING AGENCY NAME(S) AND ADDRESS(ES)

Office of the Chief of Engineers

10. SPONSORING/MONITORING AGENCY REPORT NUMBER

Washington, D.C. 210314-1000

11. SUPPLEMENTARY NOTES

For conversion of SI units to non-SI units of measurement, consult ASTM Standard E380-93, Standard Practice for Use of the International System of Units, published by the American Society for Testing and Materials, 1916 Race St., Philadelphia, Pa. 19103.

12a. DISTRIBUTION/AVAILABILITY STATEMENT 12b. DISTRIBUTION CODE

Approved for public release; distribution is unlimited.

Available from NTIS, Springfield, Virginia 22161

13. ABSTRACT (Maximum 200 words)

Strength and electrical pathways develop in snow as bonds grow among grains. Strong ice-to-ice bonds form in wet snow at low liquid contents but not in highly saturated wet snow. In freely draining wet snow, grain clusters form, and these require a certain configuration among the three phases of water. This depends somewhat on the number of grains in the cluster, but always leads to bonding. In dry snow, bonds form more slowly, but considerable strength can develop as long as rounded grains develop. The rate of bond growth is probably controlled by the temperature gradient, because both grains and bonds are observed to grow very slowly in dry snow in the absence of a temperature gradient. The basic shape of the bonds is dictated by the geometrical requirements of grain-boundary grooves and is not a simple concave neck. In dry snow, this shape, and possibly the processes, have been misunderstood.

\begin{tabular}{|c|c|c|c|}
\hline $\begin{array}{l}\text { 14. SUBJECT TERMS } \\
\text { Dry snow }\end{array}$ & Snow & & 15. NUMBER f8 PAGES \\
\hline
\end{tabular}

